Review

\title{
Primary cilium-dependent sensing of urinary flow and paracrine purinergic signaling
}

\author{
Helle A. Praetorius, Jens Leipziger* \\ Department of Biomedicine - Physiology, Aarhus University, Ole Worms Allé 6, Building 1180, 8000 Aarhus C, Denmark
}

\section{A R T I C L E I N F O}

\section{Article history:}

Available online 17 October 2012

\section{Keywords:}

Kidney

Epithelium

Tubular flow

Flow sensing

\begin{abstract}
A B S T R A C T
During the last 10 years or so, the renal research community has set the primary cilium into the lime light. From being viewed as a possible evolutionary rudiment, today the primary cilium has achieved the noble status of a physiologically relevant and necessary cellular structure. Its prime function in renal epithelium appears to be its ability to sense urinary flow. Much is still lacking to understand how the primary cilium senses flow. Transducer proteins, such as specific mechano-sensory ion channels, have been identified and are necessary for flow-dependent increases of epithelial $\left[\mathrm{Ca}^{2+}\right]_{i}$. Other ciliary receptor proteins have been suggested, which may open the field of primary cilia sensing to become an even more dynamic topic of research. A flow-induced increase of $\left[\mathrm{Ca}^{2+}\right]_{i}$ has been observed in all renal and other ciliated epithelial cells. Work over the last 5 years has addressed the mechanism underlying the flow-induced increase of $\left[\mathrm{Ca}^{2+}\right]_{i}$. It has become apparent that an initial $\mathrm{Ca}^{2+}$ influx triggers a global increase of epithelial $\left[\mathrm{Ca}^{2+}\right]_{\mathrm{i}}$. Eventually, it also became clear that mechanical stimulation of the epithelial cells triggers the release of ATP. Intriguingly, ATP is an auto- and paracrine signaling molecule that regulates electrolyte and water transport in the nephron by binding to apical and basolateral purinergic receptors. ATP inhibits transport at almost all sites from the proximal to the distal tubule and thus elicits a diuretic response. In the perspective of this review, the primary cilium is a sensory structure and the adequate stimulus is the mechanical deflection. The output signal is the released ATP, a paracrine factor that ultimately modulates the main function of the kidney, i.e. the enormous task of absorbing some 180 L of filtrate every day.
\end{abstract}

(c) 2012 Elsevier Ltd. All rights reserved.

\section{Contents}

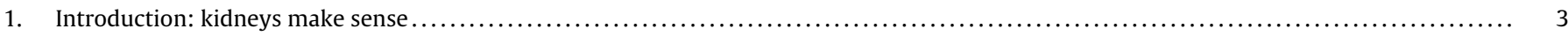

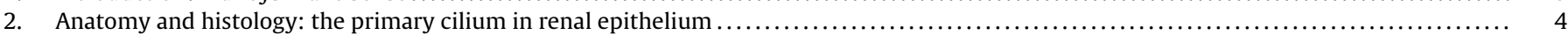

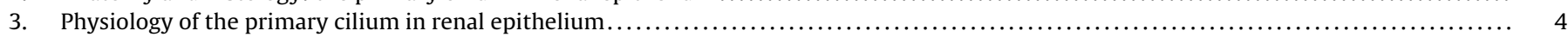

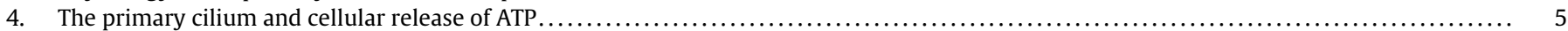

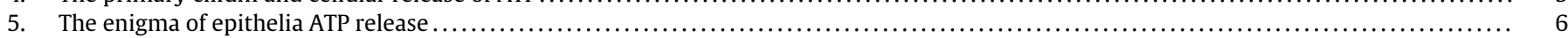

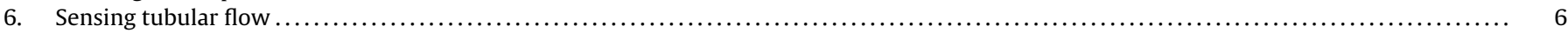

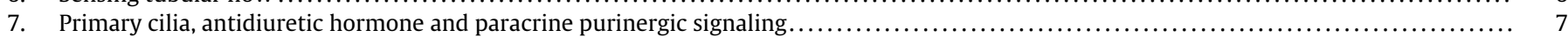

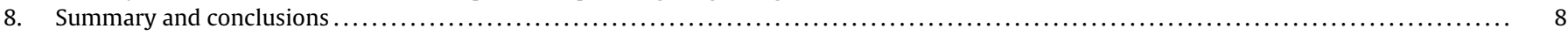

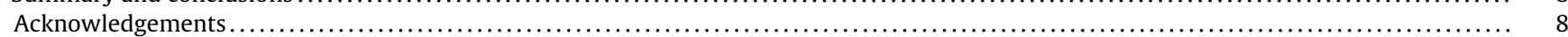

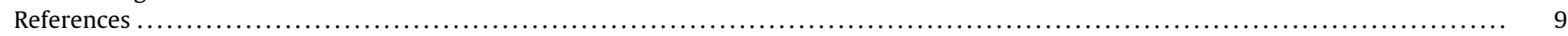

\section{Introduction: kidneys make sense}

The primary function of the kidneys is to eliminate soluble waste metabolites and excess electrolytes from our body. At first sight it appears peculiar to draw a connection between renal

\footnotetext{
* Corresponding author. Tel.: +45 87167731.

E-mail address: leip@fi.au.dk (J. Leipziger).
}

and sensory physiology. Nonetheless, it is important to understand that the kidneys are indeed classical sensory organs. Most obvious is their function as a monitor of the body's oxygen status. Hypoxia is sensed by cortical peritubular fibroblast-like cells. These cells translate hypoxia into increased erythropoietin synthesis and activation of red blood cell production in the bone marrow [1]. The "renal teleologist" would not hesitate to claim that the renal cortex is indeed the logic place to sense $\mathrm{O}_{2}$, since about $20 \%$ of the cardiac output passes through this region at an 
assured constant rate. In addition, the kidney possesses several other essential elements of sensory physiology. One unique site to register a sensory input signal is the afferent arteriole. The physical stress imposed on the afferent arteriole by increment of the blood pressure triggers a vasoconstrictor response that opposes pressure-induced passive vasodilatation. This "myogenic response" serves to keep renal blood flow and glomerular filtration rate relatively constant and protects the delicate renal glomerulus against high pressure-induced damages [2]. The molecular mechanism of pressure sensing in the afferent arteriole is still not unequivocally resolved, but involves stretch-activated influx of $\mathrm{Ca}^{2+}$ into the vascular smooth muscle cells [3]. This signal spreads via gap junctions (connexin 40), increases $\left[\mathrm{Ca}^{2+}\right]_{i}$ in the juxta-glomerular cells with a subsequent reduction of renin release [4]. Lowered plasma renin is responsible for the systemic effects that normalize blood pressure. In addition to the myogenic response, seen in many vascular beds, renal blood flow is regulated by yet another mechanism - the tubulo-glomerular feed-back mechanism (TGF). The sensory structure in this response is the salt sensing macula densa, which comprises some 10 specialized cells at the very distal part of the thick ascending limb directly adjacent to the afferent arteriole of the parent glomerulus. The macula densa senses the concentration of $\mathrm{Cl}^{-}$delivered to this segment. In the case of a high distal tubular $\mathrm{NaCl}$ load as a result of elevated filtration, the macula densa cells take up increased amounts of $\mathrm{NaCl}$ via the apical $\mathrm{Na}^{+}-\mathrm{K}^{+}-2 \mathrm{Cl}^{-}$co-transporter. The uptake of $\mathrm{Na}^{+}$and $\mathrm{Cl}^{-}$ triggers cellular swelling [5] and ATP release into the interstitial fluid surrounding the afferent arteriole. ATP is hydrolyzed via ectoenzymes (CD39 and CD73) to adenosine. In turn, adenosine acts on A1 receptors on the vascular smooth muscle cells of the afferent arteriole to trigger vasoconstriction and reduce the glomerular filtration rate for that nephron [6,7]. Tubulo-glomerular feedback prevents fluid overload for the nephron which would overburden the tubular epithelium. Tubulo-glomerular feedback contributes to auto-regulation of renal blood flow and in the regulation of systemic blood pressure. In parallel, the macula densa also regulates renin secretion from juxta-glomerular smooth muscle like cells [4]. Renin secretion is inhibited when the macula densa senses increased luminal $\mathrm{NaCl}$ concentrations.

The theme of this review series is how paracrine and autocrine signals at the periphery modulate or shape the final sensory output of the sensory organs. Intriguingly, in the sensory sites described above, the role of paracrine signals is well established and part of textbook knowledge, or it has been suggested [8]. As mentioned, the function of the macula densa critically depends on ATP release and the formation of adenosine [9]. The paracrine factors that modulate renin secretion are less well established but extracellular nucleotides similar to those described for tubule-glomerular feedback have also been suggested to play a role [4]. Moreover, the classical myogenic response may include a paracrine component. In mice deplete of the P2X1 receptor, the myogenic response was attenuated. This suggested that arterial stretch induces ATP release and P2X1-dependent contraction of the vascular smooth muscle cells [10].

Yet another issue that has evolved during the last decade links the topic of renal and sensory physiology. This is the observation that renal epithelial cells possess a single non-motile primary cilium that protrudes into the tubular lumen and likely functions as a sensory organelle. The sensory function of this cilium appears to involve paracrine signaling elements. The specific task of this review is directed toward the primary cilium as a mechano-sensory urinary flow detector. It will be discussed that deflection of the primary cilium triggers cellular ATP release and autocrine/paracrine activation of purinergic receptors in the renal tubule.

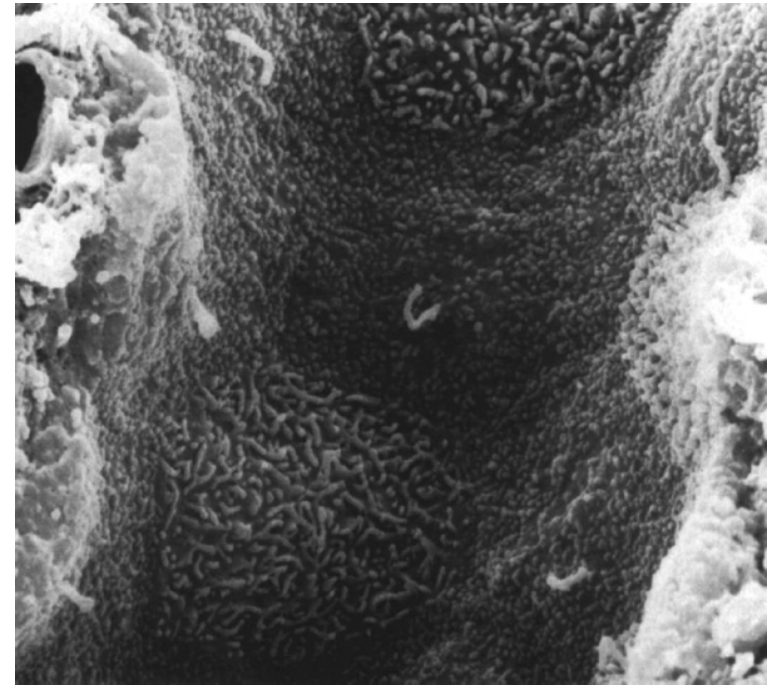

Fig. 1. Scanning electron micrograph of the apical membrane of the early inner medullary collecting duct in rat. Principal cells have microvilli and a single primary cilium. Intercalated cells are covered with numerous microprojections consisting of microplicae and a few microvilli. The figure was reproduced with permission from Kidney International and was originally generated by Kirsten Madsen, FL, USA [12]. Magnification $9000 \times$

\section{Anatomy and histology: the primary cilium in renal epithelium}

The primary cilium is a non-motile organelle found in nearly all cells with only few exceptions. For a comprehensive inventory of primary cilia reported in cells please refer to http://www.bowserlab.org/primarycilia/cilialist.html. Bone marrow-derived cells lack primary cilia [11]. In renal epithelia, only the intercalated cells of the distal tubule lack primary cilia [12]. All other renal epithelial cells express a primary cilium that protrudes perpendicularly into the lumen of the tubule. In Fig. 1a scanning electron micrograph shows the structure of the primary cilium in principal cells in the early part of a rat inner medullary collecting duct. Note the absence of primary cilia in intercalated cells. The primary cilium is $\sim 4 \mu \mathrm{m}$ in length $[11,13]$. It has a certain flexibility permitting mechanical deformation [14]. The structure of the primary cilium is defined by a microtubule-based inner skeleton called the axoneme that emerges from the mother centriole as the microtubular organization center of the cell [11]. The plasma membrane of the primary cilium is derived from the apical membrane that is enriched in specialized membrane proteins.

\section{Physiology of the primary cilium in renal epithelium}

The primary cilium has long been known as a cellular organelle with no apparent function. In 1997, elegant studies from Samuel Bowser's laboratory imaged primary cilia in living cultured renal epithelial cells [14]. In these experiments, fluid flow caused a reversible bending of the primary cilium. The degree of cilium bending was proportional to the flow rate. The authors therefore suggested that primary cilia could function as a flow sensor measuring the urinary flow rate. Some years later researchers discovered that bending the primary cilium with a micropipette or flowing solution over a layer of confluent MDCK cells in vitro triggers a robust increase of $\left[\mathrm{Ca}^{2+}\right]_{i}[15]$. This response was absent in nonconfluent cells that lack primary cilia and also disappeared when the primary cilia were chemically removed by chloral hydrate [16]. These studies concluded that the primary cilium indeed could function as a flow sensor, i.e. a change of flow over the apical surface 
of the epithelial cell elicits a cellular signaling response [11]. These results were corroborated in native renal tissue, where an increase of tubular flow triggered an increase of $\left[\mathrm{Ca}^{2+}\right]_{i}$ in rabbit cortical collecting duct [17] and in mouse medullary thick ascending limbs [13]. It became apparent that this organelle was central in the development of polycystic kidney disease. Mice that lacked Polaris, a protein that is essential for outgrowth of cilia, developed renal cysts and showed situs inversus [18]. Eventually, the gene products that cause autosomal dominant polycystic kidney disease (ADPKD) had been identified as polycystin 1 (PC-1) and polycystin 2 (PC-2) [19]. Importantly, both proteins localize to the primary cilium and form a molecular complex [20,21]. PC-2 is a member of the transient receptor potential family of sensory $\mathrm{Ca}^{2+}$ channels also called TRPP2 [22]. This suggested that TRPP2 could be part of a molecular sensor in the primary cilium that permitted $\mathrm{Ca}^{2+}$ influx and flow-mediated $\left[\mathrm{Ca}^{2+}\right]_{\mathrm{i}}$ increase. Indeed, inhibition or knock-down of either PC-1 or TRPP2 was found to block the flow response in renal epithelia $[21,23,24]$. The field of polycystic kidney research was electrified by these results because a novel and strong pathogenetic hypothesis could be put forward: In the absence of a functional primary cilium the renal epithelium lacks an essential sensory input signal to maintain its high degree of functional differentiation, eventually leading to epithelial degeneration and cyst formation.

Indeed, a cilio-centristic view emerged in this field as other defective proteins were localized to the primary cilium and were associated with renal and other organ cyst formation disorders [25]. Subsequently, the question needed to be asked whether the absence of the flow-induced increase of $\left[\mathrm{Ca}^{2+}\right]_{i}$ is an obligatory event that leads to the formation of renal cysts. $\mathrm{Ca}^{2+}$ influx due to flow-mediated deflection of the primary cilium involves the TRPP2 channel. TRP channels are often composed of several subunits, where a tetrameric structure is necessary to form a functional channel. The mechano-sensory TRPV4 channel has been identified in the primary cilium and likely forms heteromeric channels with TRPP2 [26]. In the absence of TRPV4 or when TRPV4 channels are pharmacologically inhibited, the flow response is blocked. Importantly, TRPV4 knock-out mice do not develop renal cysts. This provides a significant argument that the absence of the flowmediated increase of $\left[\mathrm{Ca}^{2+}\right]_{i}$ is not directly linked to the formation of cysts. Today, the mechanism by which primary cilium dysfunction leads to the formation of renal cysts remains to be understood. Nonetheless, many observations support the notion that primary cilia function as sensory organelles. The physiology of the primary cilium in the kidney is just emerging.

\section{The primary cilium and cellular release of ATP}

A flow-stimulated increase of $\left[\mathrm{Ca}^{2+}\right]_{\mathrm{i}}$ in renal and other ciliated epithelial cells has now been observed in many different epithelia $[23,26-28]$. The consensus is that the response is triggered by an initial influx of $\mathrm{Ca}^{2+}$ at the apical membrane via the pathway discussed above. Eventually, $\left[\mathrm{Ca}^{2+}\right]_{\mathrm{i}}$ increases throughout the cytosol due to release from intracellular stores. In MDCK cells, $\mathrm{Ca}^{2+}$ is released from IP3-sensitive compartments [15]. This has raised the question whether deflecting the cilium released a paracrine factor, activated a Gq protein-coupled receptor, and generated IP3. Moreover, mechanical stimulation of cells due to swelling [29], gentle handling of a cell culture dish [30], imposing a transepithelial hydrostatic pressure gradient [31], or touching a cell with a micropipette [32], commonly triggers ATP release. We are tempted to suggest that any mechanical stimulation of cells may induce nonlytic ATP release. In this context, it is noteworthy that the flow response in the collecting duct is also found in intercalated cells, which do not have primary cilia [17].
Thus, it was logical to hypothesize that deflecting the primary cilium triggers ATP release. This phenomenon was first studied in the isolated perfused renal tubule. Increasing tubular flow triggered an increase in $\left[\mathrm{Ca}^{2+}\right]_{i}[13]$. The same experiments were also performed in renal tubules from mice lacking P2Y2 receptors (knock-out mice). In those experiments, the response to tubular flow was markedly reduced [13]. Further experiments were conducted using the P2 receptor blocker suramin and scavenging extracellular ATP with apyrase, an ATP hydrolyzing enzyme. In both cases, the flow response was markedly attenuated, especially when the blockers were applied to the luminal fluid compartment [13]. These results strongly suggested that tubular flow triggers ATP release, followed by auto-and paracrine activation of epithelial P2 receptors. A direct link to the primary cilium could not be established in these experiments. It is interesting to note, however, that in mice with truncated primary cilia due to a mutation in the orpk gene, flow-stimulated increase of $\left[\mathrm{Ca}^{2+}\right]_{i}$ was attenuated [33].

Obviously, the increase of flow in the native tubule will bend the primary cilia. At the same time, however, renal tubules are significantly distended ( 20\%) during increased flow $[13,17,33]$. Thus, the mechanical stimulus to the tubular epithelium is complex and may involve pathways other than the primary cilium that trigger ATP release. To study if ATP release is dependent on the primary cilium we again used the MDCK cell system [34]. Cells were grown on half glass cover slips and mounted into a flow chamber (Fig. 2). Confluent cells were placed up-stream in the flow path. Directly adjacent to, but not directly touching the confluent MDCK cells, we positioned non-confluent MDCK cells that respond to extracellular ATP [34]. These non-confluent MDCK cells functioned as bio-sensor cells for extracellular ATP. When a mechanical stimulus (flow) was applied to the confluent cells, there was an increase of $\left[\mathrm{Ca}^{2+}\right]_{i}$, as expected [16,34]. Intriguingly, the downstream biosensor cells also showed an increase in $\left[\mathrm{Ca}^{2+}\right]_{\mathrm{i}}$, which is normally not elicited by flow in these nonciliated cells [34]. The findings suggested that a paracrine signal was released from the confluent MDCK cells and washed over the adjacent cells. The paracrine factor was subsequently identified as ATP. Apyrase and P2 receptor blockers inhibited the biosensor responses [34]. Noteworthy, after removing primary cilia with chloral hydrate, the flow-stimulated increase of $\left[\mathrm{Ca}^{2+}\right]_{i}$ was completely absent in the confluent MDCK cells and in the adjacent biosensor cells [34]. These findings indicate that flow-stimulated ATP release into the luminal fluid space in renal tubules requires the primary cilium.

Research from other laboratories has confirmed that flow over the apical membrane triggers ATP secretion in kidney epithelial cells [27,35]. Furthermore, in ciliated cells from the bile duct, flow was also found to trigger ATP release into to luminal fluid space [36]. In renal epithelial cells from a patient with autosomal dominant polycystic kidney disease (ADPKD) caused by a defect in polycystin 1 , flow-stimulated ATP release was significantly reduced [27]. Genetic rescue of orpk ADPKD mouse epithelial cells led to the reappearance of primary cilia and a concurrent rescue of ATP secretion triggered by fluid flow [35].

Collectively, the data support the notion that intact primary cilia are required for epithelial ATP secretion. The compiled data provide a sound basis for an improved understanding of the flowstimulated increase of $\left[\mathrm{Ca}^{2+}\right]_{i}$ in renal and other ciliated epithelial cells. The cilium functions as a mechano-sensory fluid flow detector, the deflection of which triggers the release of nucleotides. These nucleotides stimulate epithelial P2 receptors in an autocrine and paracrine manner and trigger an intracellular increase in $\mathrm{Ca}^{2+}$. It is likely that ATP is released into the interstitial fluid surrounding the basolateral membrane but this remains to be studied [31]. These results therefore provide further support that the primary cilium is a sensory structure of physiological relevance. 
A

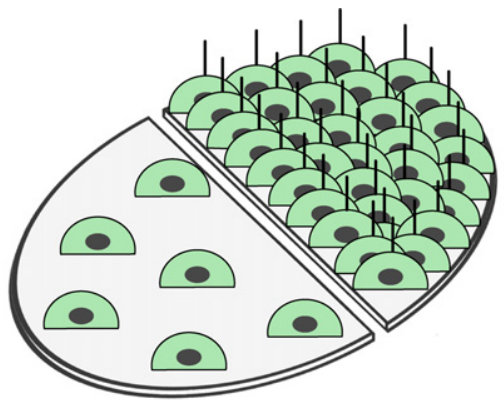

\section{No flow} Intact cilia

B

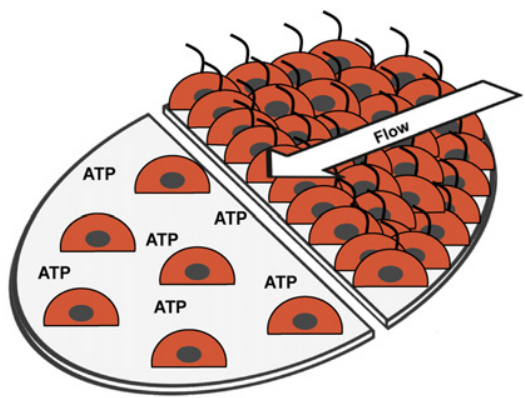

Flow Intact cilia
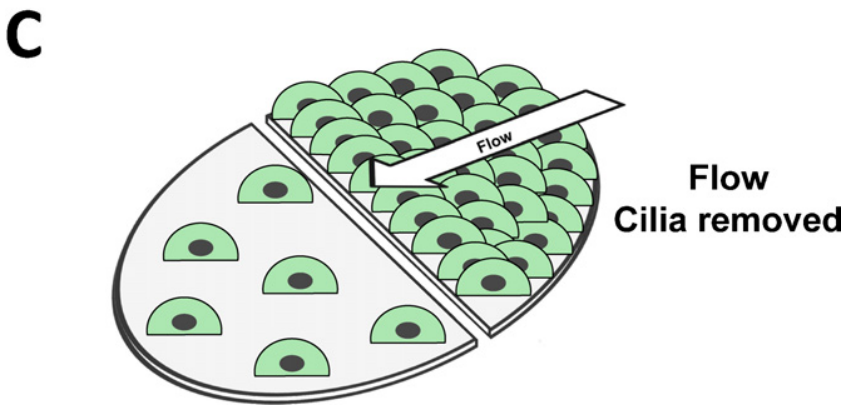

Fig. 2. Schematic view of flow chamber experiments to study cilium-dependent release of ATP. (A) Before flow is started. Confluent ciliated MDCK cells are positioned "up-stream" of the non-confluent MDCK biosensor cells. (B) Flow is started and an intracellular $\mathrm{Ca}^{2+}$ increase is recorded. The confluent cells respond with a flowinduced increase of $\left[\mathrm{Ca}^{2+}\right]_{i}$. Importantly, non-confluent biosensor cells also respond with a prominent increase of $\left[\mathrm{Ca}^{2+}\right]_{i}$. ATP mediates the response in biosensor cells. (C) In deciliated cells, there is no response to flow.

\section{The enigma of epithelia ATP release}

Non-lytic ATP release has been demonstrated in many cell types and this provides the extracellular nucleotides for paracrine purinergic signaling. It is important to define the molecular mechanism of cellular ATP release. Significant progress has lead to two major suggestions. ATP may be secreted via vesicular exocytosis or via a conductive channel [37]. In several cells, the plasma membrane protein pannexin-1 has been associated with cellular ATP release and has become a prime candidate for further research. In renal epithelia, the mechanism of ATP release is largely unresolved and different players have been suggested. In the apical membrane of collecting duct intercalated cells, connexin 30 has been suggested as a conductive pathway for ATP secretion [38]. Connexon 30 in the apical membrane could function as a hemichannel. In the thick ascending limb, connexin 37 is found in the basolateral membrane. Most likely, connexin 37 does not form gap junctions at that site [39] and might be an ATP release channel there. The further study of epithelial ATP release is in our view an important question to be addressed.

\section{Sensing tubular flow}

The proposition that the primary cilium acts as flow measuring device is fascinating. The important question in this context is what could be an appropriate response for the physiology of the renal tubule? One hypothesis has been mentioned above while discussing the primary cilium and the link to polycystic kidney disease. It is possible that the tubular epithelial cell needs to be informed about being in proper use. This information would be sensed by measuring pre-urine flow, which is translated into cellular signaling events such as paracrine/autocrine release of ATP. These signals presumably regulate essential cellular features necessary to ascertain tubular structure and function. This concept lends its inspiration from the very general biological viewpoint, which uses the snappy term "use it or lose it". Numerous suggestions for how flow could affect the cell via primary cilia sensing have been put forward. Recent data suggest a role of mTOR1 signaling and cell size regulation [23], hedgehog signaling [40] and the WNT signaling pathway [41]

Renal tubular flow shows significant diurnal variability as the body goes through periods of high and low fluid intake. During high fluid intake and systemic volume expansion, the kidneys respond with diuresis. Diuresis is associated with an increase in glomerular filtration rate paralleled by reduced tubular absorption. Tubular transport along the renal tubule is a highly regulated process and the change of tubular flow rates could be isolated as one important regulatory event.

Such a regulation of tubular transport is best illustrated by $\mathrm{K}^{+}$ secretion in the distal renal tubule. It has long been known that $\mathrm{K}^{+}$secretion is under the control of many factors, including the tubular flow rate $[42,43]$. The initial part of the distal tubule is the site of active $\mathrm{K}^{+}$secretion. In the connecting tubule and early collecting duct, a physiological increase of tubular flow rates from 0.5 to $6 \mathrm{nl} \mathrm{min}^{-1}$ increases $\mathrm{K}^{+}$secretion markedly [43]. This has been attributed to a more favorable $\mathrm{K}^{+}$gradient during higher flow conditions and to an increased $\mathrm{Na}^{+}$load to this tubular site [44]. Studies identified that the voltage and $\mathrm{Ca}^{2+}$-dependent BK channel (KCa1.1) mediates flow-stimulated distal tubular $\mathrm{K}^{+}$secretion [45]. Our current understanding is that a parallel action of the ROMK channel in the principal cells and the BK channel in the distal tubule is responsible for renal $\mathrm{K}^{+}$secretion $[46,47] . \mathrm{K}^{+}$ secretion mediated by the BK channel is likely prominent during $\mathrm{K}^{+}$adaptation after prolonged high $\mathrm{K}^{+}$intake $[47,48]$. It is noteworthy that the BK channel is also responsible for $\mathrm{K}^{+}$secretion in the distal colon [49]. In our experiments, distal colonic $\mathrm{K}^{+}$secretion became apparent when luminal P2Y receptors were stimulated [50]. This raises the question whether renal tubular ATP signaling also plays a role in flow-stimulated $\mathrm{K}^{+}$secretion. It is well established that the entire distal tubule expresses apical P2Y receptors [51]. Intriguingly, flow-induced increase of $\mathrm{K}^{+}$secretion was completely absent in TRPV4 knock-out mice [52]. As mentioned above, the TRPV4 channel is postulated to be a molecular component of the ciliary mechano-sensory $\mathrm{Ca}^{2+}$ channel [26]. Absence of TRPV4 channels leads to blocked flow-induced increase of tubular $\left[\mathrm{Ca}^{2+}\right]_{i}$ [26]. These combined results suggest that a flow-induced increase of $\mathrm{K}^{+}$secretion involves an active cellular sensing mechanism that opens epithelial $\mathrm{Ca}^{2+}$ and $\mathrm{K}^{+}$channels. We therefore speculate the model depicted in Fig. 3. Flow triggers the deflection of the primary cilium to induce ATP release and paracrine activation of apical (possibly also basolateral) P2 receptors. Stimulation of P2 receptors causes an increase in $\left[\mathrm{Ca}^{2+}\right]_{i}$ that opens apical BK channels and elicits $\mathrm{K}^{+}$secretion. Thus, we hypothesize that local release of ATP represents a paracrine factor to facilitate renal $\mathrm{K}^{+}$excretion.

This hypothesis will require further experiments and rigorous testing. The renal tubule expresses numerous apical and basolateral P2 receptors along its entire length. Pharmacological activation of renal tubular P2 receptors markedly inhibits ion and water absorption. This contrasts with the purinergic activation of $\mathrm{K}^{+}$ secretion through BK channels, discussed above. Examples of P2 


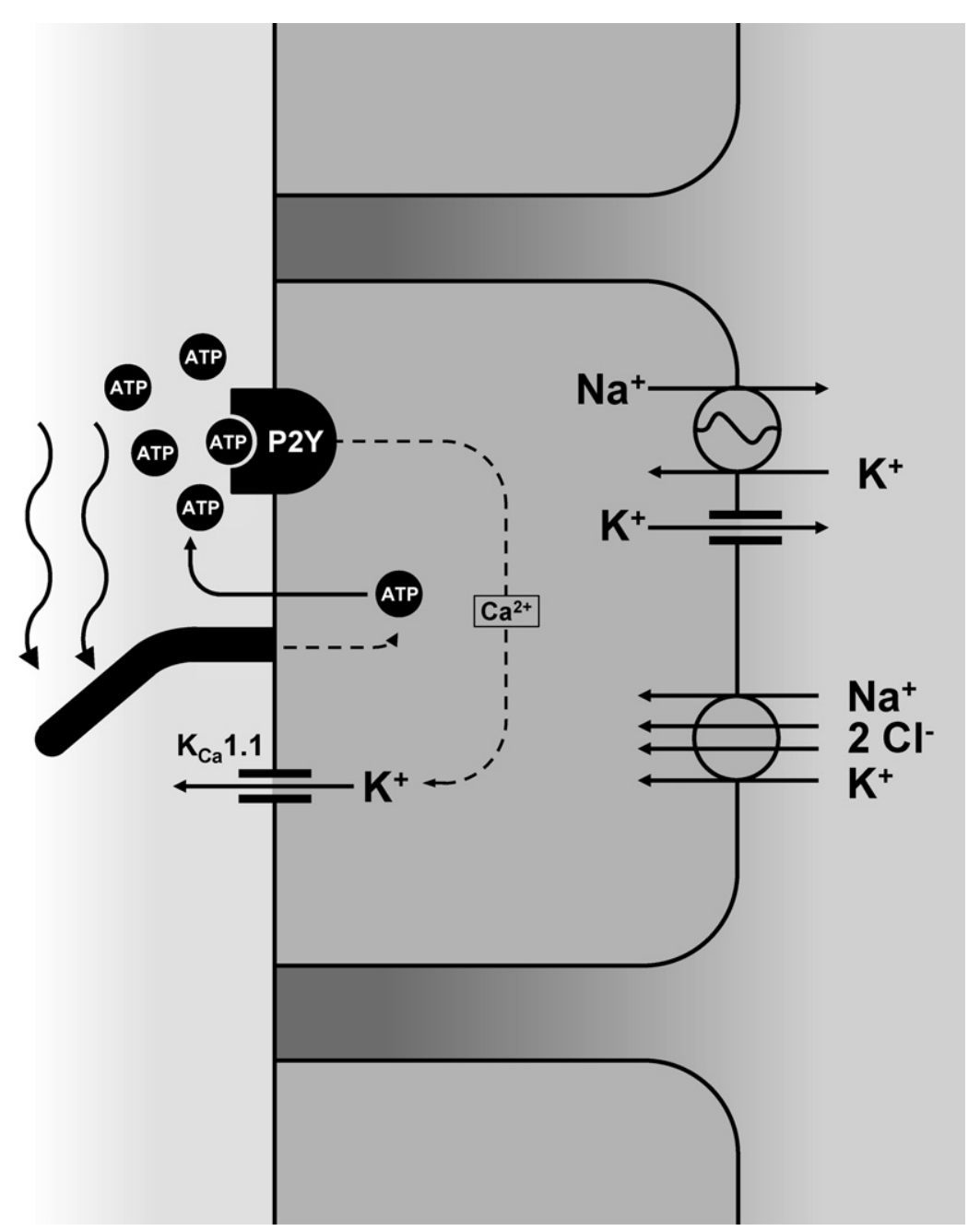

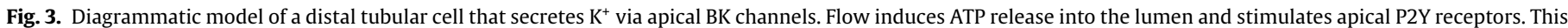
in turn increases epithelial $\left[\mathrm{Ca}^{2+}\right]_{\mathrm{i}}$ and opens BK channels.

receptor-mediated inhibition of renal transport include $\mathrm{HCO}^{-}$ absorption in the proximal tubule, $\mathrm{NaCl}$ absorption in the thick ascending limb, $\mathrm{Na}^{+}$absorption in the collecting duct, and water transport in the inner medullary collecting duct. The concentration of ATP in the tubular lumen is sufficiently high to inhibit transport tonically $[53,54]$. ATP in the lumen is derived from local release from tubular epithelial cells [37]. Tubular ATP release is constitutive [54] and is further enhanced by stimulation of G-protein coupled receptors [54] and after increased tubular flow [13,27,35]. In the absence of relevant renal epithelial P2 receptors, such as P2Y2 receptors, there is excess absorption of $\mathrm{Na}^{+}$that leads to elevated blood pressure and a suppressed renin-angiotensin-aldosterone system. These results reinforce the notion that extracellular nucleotides provide a tonic input signal to reduce tubular absorption. ATP in the tubular lumen appears to function as an endogenous local diuretic system which facilitates the excretion of fluid (Fig. 4).

Tubular flow and pressure change significantly as a function of oscillations in the flow in the early proximal tubule. These oscillations are caused by spontaneous changes in the diameter of the afferent arteriole or by discontinuous outflow conditions at the renal papilla. One might envision that tubular flow and pressure changes alter the deflection of apical cilia and thus alter ATP secretion into the tubular fluid. In this hypothesis, the primary cilium would play a role in maintaining luminal ATP concentrations and stimulating a diuretic response.

\section{Primary cilia, antidiuretic hormone and paracrine purinergic signaling}

Primary cilia are mechanosensory and chemosensory. In Caenorhabditis elegans, primary cilia are present on the sensory neurons that respond to touch and to various chemo-attractants [55-57]. Certain receptors are found to be particularly abundant and are functional in the membrane of the primary cilia $[55,58,59]$. Interestingly, vasopressin V2 receptors have been localized to the ciliary membrane in renal tubules [60]. In the distal part of the renal tubule the effect of arginine vasopressin (AVP) is mediated via V2 receptors. V2 receptors are believed to be expressed in the basolateral membrane of distal tubular epithelia. When stimulated, these receptors elicit a cAMP-and $\left[\mathrm{Ca}^{2+}\right]_{i}$-dependent trafficking of aquaporin channels (AQP2) to the apical membrane [61]. The localization of $\mathrm{V} 2$ receptors to the ciliary membrane opens the possibility that AVP may act apically as well as basolaterally. Urinary $A V P$ is present in concentrations sufficient to stimulate $V 2$ receptors (5-500 pM) [62]. Of particular interest in this regard is the investigation of patients with the ciliopathy, Bardet-Biedl syndrome. This complex syndrome is caused by mutations of at least 14 different genes that are related to defects in the basal body/primary cilium complex [63]. One of the manifestations of the syndrome is a urinary concentration defect [60]. Marion et al. [60] found that ciliary V2 receptors appear to be responsible for the apical actions of AVP. Epithelia lacking cilia due to Bardet-Biedl-type 


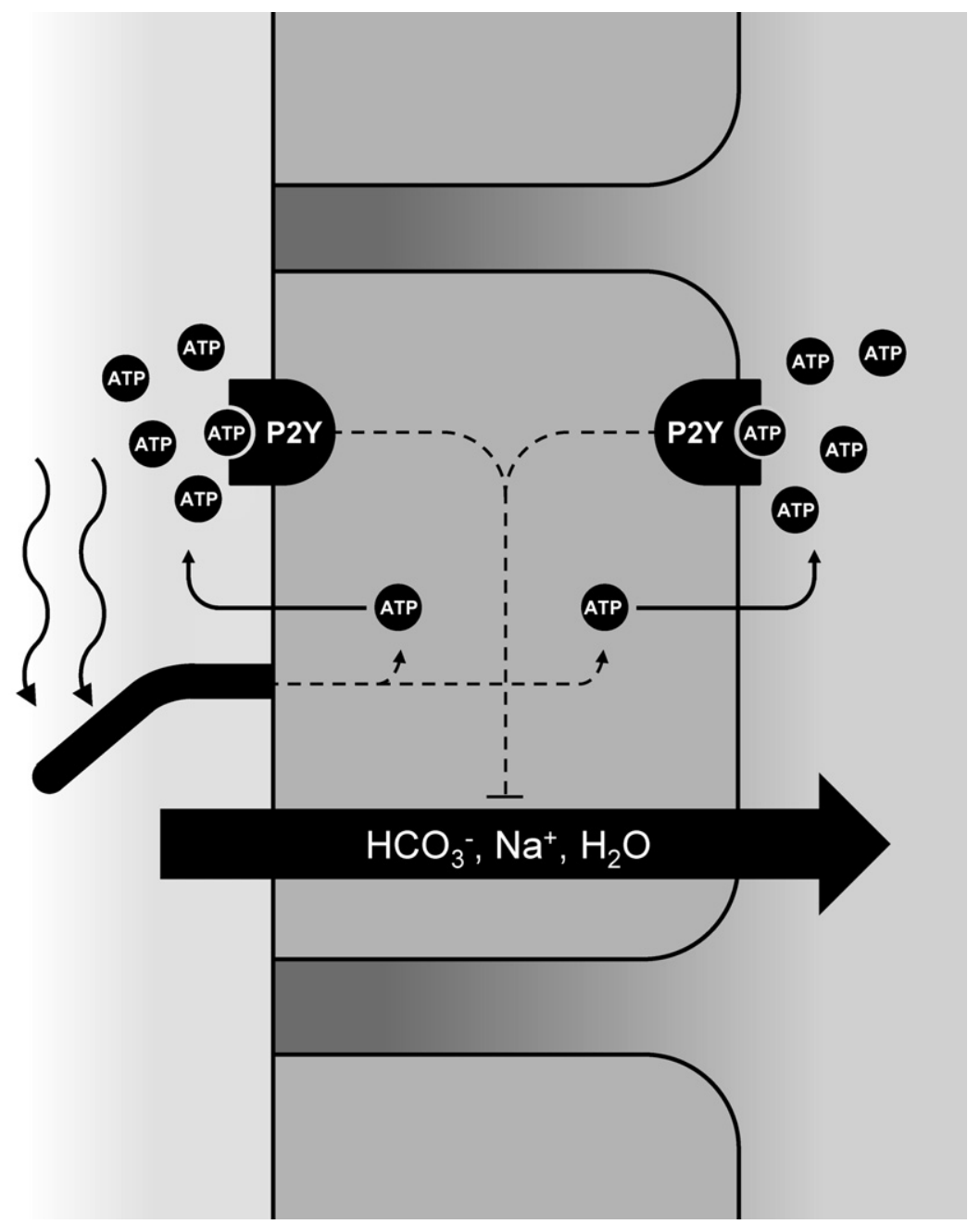

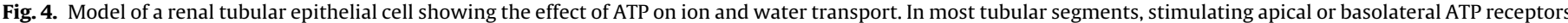

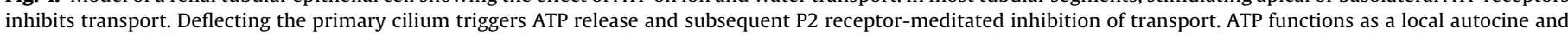
paracrine diuretic factor.

mutations lost the apical AVP response, both in terms of cAMP production and trafficking of aquaporin channels [60]. This loss was rescued by forskolin, which elevates intracellular cAMP in a receptor-independent fashion [60]. These data suggest a role for the primary cilium in detecting urinary AVP to regulate tubular water permeability. Interestingly, stimulation of V2 receptors with AVP is known to release ATP both in the thick ascending limb and in the cortical collecting duct [54]. ATP is known to counteract the transport effects of AVP and may thus be a negative feedback mechanism that prevents overstimulation of the tissue.

\section{Summary and conclusions}

During the last decade, the renal research community has set the primary cilium into the lime light. From being viewed as a possible evolutionary rudiment, today the primary cilium has achieved the noble status of a physiologically relevant and necessary cellular structure. Its prime function in renal epithelium appears to be its ability to sense urinary flow. Much is still lacking to understand how the primary cilium senses flow. Transducer proteins, such as specific mechano-sensory ion channels, have been identified and are necessary for flow-dependent increases of epithelial $\left[\mathrm{Ca}^{2+}\right]_{\mathrm{i}}$. Other ciliary receptor proteins have been suggested, which may open the field of primary cilia sensing to become an even more dynamic topic of research. A flow-induced increase of $\left[\mathrm{Ca}^{2+}\right]_{i}$ has been observed in all renal and other ciliated epithelial cells. Work over the last 5 years has addressed the mechanism underlying the flow-induced increase of $\left[\mathrm{Ca}^{2+}\right]_{\mathrm{i}}$. It has become apparent that an initial $\mathrm{Ca}^{2+}$ influx triggers a global increase of epithelial $\left[\mathrm{Ca}^{2+}\right]_{i}$. Eventually, it also clear that mechanical stimulation of the epithelial cells triggers the release of ATP into the surrounding extracellular fluid space. Intriguingly, ATP is an auto-and paracrine signaling molecule that regulates electrolyte and water transport in the nephron by binding to apical and basolateral purinergic receptors. ATP inhibits transport at almost all sites from the proximal to the distal tubule and thus elicits a diuretic response. In the perspective of this review, the primary cilium is a sensory structure and the adequate stimulus is the mechanical deflection. The output signal is the released ATP, a paracrine factor that ultimately modulates the main function of the kidney, i.e. the enormous task of absorbing some 180 liter of filtrate every day.

\section{Acknowledgements}

We are greatly indebted to Casper K. Larsen for helping to produce the figures of this review. 


\section{References}

[1] Wenger RH, Hoogewijs D. Regulated oxygen sensing by protein hydroxylation in renal erythropoietin-producing cells. American Journal of Physiology: Renal Physiology 2010;298:F1287-96.

[2] Loutzenhiser R, Griffin K, Williamson G, Bidani A. Renal autoregulation: new perspectives regarding the protective and regulatory roles of the underlying mechanisms. American Journal of Physiology: Regulatory, Integrative and Comparative Physiology 2006;290:R1153-67.

[3] Sharif-Naeini R, Dedman A, Folgering JH, Duprat F, Patel A, Nilius B, et al. TRP channels and mechanosensory transduction: insights into the arterial myogenic response. Pflugers Archives 2008;456:529-40.

[4] Kurtz A. Renin release: sites, mechanisms, and control. Annual Review of Physiology 2010.

[5] Gonzalez E, Salomonsson M, Muller-Suur C, Persson AE. Measurements of macula densa cell volume changes in isolated and perfused rabbit cortical thick ascending limb II. Apical and basolateral cell osmotic water permeabilities. Acta Physiologica Scandinavica 1988;133:159-66.

[6] Brown R, Ollerstam A, Johansson B, Skott O, Gebre-Medhin S, Fredholm B, et al. Abolished tubuloglomerular feedback and increased plasma renin in adenosine A1 receptor-deficient mice. American Journal of Physiology: Regulatory, Integrative and Comparative Physiology 2001;281:R1362-7.

[7] Sun D, Samuelson LC, Yang T, Huang Y, Paliege A, Saunders T, et al. Mediation of tubuloglomerular feedback by adenosine: evidence from mice lacking adenosine 1 receptors. Proceedings of the National Academy of Sciences of the United States of America 2001;98:9983-8.

[8] Schnermann J, Levine DZ. Paracrine factors in tubuloglomerular feedback: adenosine, ATP, and nitric oxide. Annual Review of Physiology 2003;65:501-29.

[9] Oppermann M, Friedman DJ, Faulhaber-Walter R, Mizel D, Castrop H, Enjyoji $\mathrm{K}$, et al. Tubuloglomerular feedback and renin secretion in NTPDase1/CD39-deficient mice. American Journal of Physiology: Renal Physiology 2008;294:F965-70.

[10] Inscho EW. ATP, P2 receptors and the renal microcirculation. Purinergic Signal 2009;5:447-60.

[11] Praetorius HA, Spring KR. A physiological view of the primary cilium. Annual Review of Physiology 2005;67:515-29.

[12] Madsen KM, Clapp WL, Verlander JW. Structure and function of the inner medullary collecting duct. Kidney International 1988;34:441-54.

[13] Jensen ME, Odgaard E, Christensen MH, Praetorius HA, Leipziger J. Flowinduced $\left[\mathrm{Ca}^{2+}\right]_{\mathrm{i}}$ increase depends on nucleotide release and subsequent purinergic signaling in the intact nephron. Journal of the American Society of Nephrology 2007;18:2062-70.

[14] Schwartz EA, Leonard ML, Bizios R, Bowser SS. Analysis and modeling of the primary cilium bending response to fluid shear. American Journal of Physiology 1997;272:F132-8.

[15] Praetorius HA, Spring KR. Bending the MDCK cell primary cilium increases intracellular calcium. Journal of Membrane Biology 2001;184:71-9.

[16] Praetorius HA, Spring KR. Removal of the MDCK cell primary cilium abolishes flow sensing. Journal of Membrane Biology 2003;191:69-76.

[17] Woda CB, Leite Jr M, Rohatgi R, Satlin LM. Effects of luminal flow and nucleotides on $\left[\mathrm{Ca}^{2+}\right]_{i}$ in rabbit cortical collecting duct. American Journal of Physiology: Renal Physiology 2002;283:F437-46.

[18] Murcia NS, Richards WG, Yoder BK, Mucenski ML, Dunlap JR, Woychik RP. The oak ridge polycystic kidney (orpk) disease gene is required for left-right axis determination. Development 2000;127:2347-55.

[19] Harris PC. 2008 Homer W. Smith Award: insights into the pathogenesis of polycystic kidney disease from gene discovery. Journal of the American Society of Nephrology 2009;20:1188-98.

[20] Hanaoka K, Qian F, Boletta A, Bhunia AK, Piontek K, Tsiokas L, et al. Co-assembly of polycystin-1 and -2 produces unique cation-permeable currents. Nature 2000;408:990-4.

[21] Nauli SM, Alenghat FJ, Luo Y, Williams E, Vassilev P, Li X, et al. Polycystins 1 and 2 mediate mechanosensation in the primary cilium of kidney cells. Nature Genetics 2003;33:129-37.

[22] Nilius B, Owsianik G, Voets T, Peters JA. Transient receptor potential cation channels in disease. Physiological Reviews 2007;87:165-217.

[23] Boehlke C, Kotsis F, Patel V, Braeg S, Voelker H, Bredt S, et al. Primary cilia regulate mTORC1 activity and cell size through Lkb1. Nature Cell Biology 2010;12:1115-22.

[24] Kotsis F, Nitschke R, Doerken M, Walz G, Kuehn EW. Flow modulates centriole movements in tubular epithelial cells. Pflugers Archives 2008;456:1025-35.

[25] Watnick T, Germino G. From cilia to cyst. Nature Genetics 2003;34:355-6.

[26] Kottgen M, Buchholz B, Garcia-Gonzalez MA, Kotsis F, Fu X, Doerken M, et al. TRPP2 and TRPV4 form a polymodal sensory channel complex. Journal of Cell Biology 2008;182:437-47.

[27] Xu C, Shmukler BE, Nishimura K, Kaczmarek E, Rossetti S, Harris PC, et al. Attenuated, flow-induced ATP release contributes to absence of flow-sensitive, purinergic $\mathrm{Ca}^{2+}$ signaling in human ADPKD cyst epithelial cells. American Journal of Physiology: Renal Physiology 2009;296:F1464-76.

[28] Masyuk AI, Masyuk TV, Splinter PL, Huang BQ, Stroope AJ, LaRusso NF. Cholangiocyte cilia detect changes in luminal fluid flow and transmit them into intracellular $\mathrm{Ca}^{2+}$ and cAMP signaling. Gastroenterology 2006;131:911-20.

[29] Boudreault F, Grygorczyk R. Cell swelling-induced ATP release is tightly dependent on intracellular calcium elevations. Journal of Physiology 2004;561:499-513.
[30] Harden TK, Lazarowski ER, Boucher RC. Release, metabolism and interconversion of adenine and uridine nucleotides: implications for G protein-coupled P2 receptor agonist selectivity trends. Pharmacological Sciences 1997;18:43-6.

[31] Praetorius HA, Frokiaer J, Leipziger J. Transepithelial pressure pulses induce nucleotide release in polarized MDCK cells. American Journal of Physiology: Renal Physiology 2005;288:F133-41.

[32] Enomoto K-I, Furuya K, Yamagishi S, Oka T, Maeno T. The increase in the intracellular $\mathrm{Ca}^{2+}$ concentration induced by mechanical stimulation is propagated via release of pyrophosphorylated nucleotides in mammary epithelial cells. Pflügers Archiv European Journal of Physiology 1994;427:533-42.

[33] Liu W, Murcia NS, Duan Y, Weinbaum S, Yoder BK, Schwiebert EM, et al. Mechanoregulation of intracellular $\mathrm{Ca}^{2+}$ concentration is attenuated in collecting duct of monocilium-impaired orpk mice. American Journal of Physiology: Renal Physiology 2005;289:F978-88.

[34] Praetorius HA, Leipziger J. Released nucleotides amplify the ciliumdependent, flow-induced $\left[\mathrm{Ca}^{2+}\right]_{i}$ response in MDCK cells. Acta Physiologiae 2009; $197: 241-51$.

[35] Hovater MB, Olteanu D, Hanson EL, Cheng NL, Siroky B, Fintha A, et al. Loss of apical monocilia on collecting duct principal cells impairs ATP secretion across the apical cell surface and ATP-dependent and flow-induced calcium signals. Purinergic Signal 2008;4:155-70.

[36] Woo K, Dutta AK, Patel V, Kresge C, Feranchak AP. Fluid-flow induces mechanosensitive ATP release, calcium signaling, and $\mathrm{Cl}^{-}$transport in bilary epithelial cells through a PKCæ-dependent pathway. Journal of Physiology 2008;586:2779-98.

[37] Praetorius HA, Leipziger J. ATP release from non-excitable cells. Purinergic Signal 2009;5:433-46.

[38] Sipos A, Vargas SL, Toma I, Hanner F, Willecke K, Peti-Peterdi J. Connexin 30 deficiency impairs renal tubular ATP release and pressure natriuresis. Journal of the American Society of Nephrology 2009;20:1724-32.

[39] Stoessel A, Himmerkus N, Bleich M, Bachmann S, Theilig F. Connexin 37 is localized in renal epithelia and responds to changes in dietary salt intake. American Journal of Physiology: Renal Physiology 2010;298:F216-23.

[40] Wong SY, Reiter JF. The primary cilium at the crossroads of mammalian hedgehog signaling. Current Topics in Developmental Biology 2008;85:225-60.

[41] Corbit KC, Shyer AE, Dowdle WE, Gaulden J, Singla V, Chen MH, et al. Kif3a constrains beta-catenin-dependent Wnt signalling through dual ciliary and non-ciliary mechanisms. Nature Cell Biology 2008;10:70-6.

[42] Kunau Jr RT, Webb HL, Borman SC. Characteristics of the relationship between the flow rate of tubular fluid and potassium transport in the distal tubule of the rat. Journal of Clinical Investigation 1974;54:1488-95.

[43] Malnic G, Berliner RW, Giebisch GH. Flow dependence of $\mathrm{K}^{+}$secretion in cortical distal tubules of the rat. American Journal of Physiology 1989;256:F932-41.

[44] Giebisch GH. Renal potassium transport: mechanism and regulation. American Journal of Physiology: Renal Physiology 1998;274:F817-33.

[45] Woda CB, Bragin A, Kleyman TR, Satlin LM. Flow-dependent $\mathrm{K}^{+}$secretion in the cortical collecting duct is mediated by a maxi-K channel. American Journal of Physiology: Renal Physiology 2001;280:F786-93.

[46] Sansom SC, Welling PA. Two channels for one job. Kidney International 2007;72:529-30.

[47] Rieg T, Vallon V, Sausbier M, Sausbier U, Kaissling B, Ruth P, et al. The role of the BK channel in potassium homeostasis and flow-induced renal potassium excretion. Kidney International 2007;72:566-73.

[48] Frindt G, Palmer LG. $\mathrm{K}^{+}$secretion in the rat kidney: $\mathrm{Na}^{+}$channel-dependent and -independent mechanisms. American Journal of Physiology: Renal Physiology 2009;297:F389-96.

[49] Sausbier M, Matos JE, Sausbier U, Beranek G, Arntz C, Neuhuber W, et al. Distal colonic $\mathrm{K}^{+}$secretion occurs via BK channels. Journal of the American Society of Nephrology 2006;17:1275-82.

[50] Matos JE, Robaye B, Boeynaems JM, Beauwens R, Leipziger J. $\mathrm{K}^{+}$secretion activated by luminal P2Y2 and P2Y4 receptors in mouse colon. Journal of Physiology 2005;564:269-79.

[51] Leipziger J. Control of epithelial transport via luminal P2 receptors. American Journal of Physiology: Renal Physiology 2003;284:F419-32.

[52] Taniguchi J, Tsuruoka S, Mizuno A, Sato J, Fujimura A, Suzuki M. TRPV4 as a flow sensor in flow-dependent $\mathrm{K}^{+}$secretion from the cortical collecting duct. American Journal of Physiology: Renal Physiology 2007;292:F667-73.

[53] Vekaria RM, Unwin RJ, Shirley DG. Intraluminal ATP concentrations in rat renal tubules. Journal of the American Society of Nephrology 2006;17:1841-7.

[54] Odgaard E, Praetorius HA, Leipziger J. AVP-stimulated nucleotide secretion in perfused mouse medullary thick ascending limb and cortical collecting duct. American Journal of Physiology: Renal Physiology 2009;297:F341-9.

[55] Liedtke W, Tobin DM, Bargmann CI, Friedman JM. Mammalian TRPV4 (VR-OAC) directs behavioral responses to osmotic and mechanical stimuli in Caenorhabditis elegans. Proceedings of the National Academy of Sciences of the United States of America 2003;100(Suppl. 2):14531-6.

[56] Barr MM, Sternberg PW. A polycystic kidney-disease gene homologue required for male mating behaviour in C. elegans. Nature 1999;401:386-9.

[57] Colbert HA, Smith TL, Bargmann CI. OSM-9, a novel protein with structural similarity to channels, is required for olfaction, mechanosensation, and olfactory adaptation in Caenorhabditis elegans. Journal of Neuroscience 1997; 17:8259-69.

[58] Handel M, Schulz S, Stanarius A, Schreff M, Erdtmann-Vourliotis M, Schmidt H, et al. Selective targeting of somatostatin receptor 3 to neuronal cilia. Neuroscience 1999;89:909-26. 
[59] Iwanaga T, Miki T, Takahashi-Iwanaga H. Restricted expression of somatostatin receptor 3 to primary cilia in the pancreatic islets and adenohypophysis of mice. Biomedical Research 2011;32:73-81.

[60] Marion V, Schlicht D, Mockel A, Caillard S, Imhoff O, Stoetzel C, et al. Bardet-Biedl syndrome highlights the major role of the primary cilium in efficient water reabsorption. Kidney International 2011;79: 1013-25.
[61] Knepper MA, Nielsen S, Chou CL, DiGiovanni SR. Mechanism of vasopressin action in the renal collecting duct. Seminars in Nephrology 1994;14:302-21.

[62] Naruse M, Yoshitomi K, Hanaoka K, Imai M, Kurokawa K. Electrophysiological study of luminal and basolateral vasopressin in rabbit cortical collecting duct. American Journal of Physiology 1995;268:F20-9.

[63] Zaghloul NA, Katsanis N. Mechanistic insights into Bardet-Biedl syndrome, a model ciliopathy. Journal of Clinical Investigation 2009;119:428-37. 